\title{
Ultrastructure of Glassy-winged Sharpshooter Mouthparts and Salivary Sheaths.
}

*Thomas Freeman, **Roger Leopold, **James Buckner, ** Dennis Nelson

*Electron Microscopy Center, North Dakota State University, Northern Crop Science Laboratory, 1307 N. $18^{\text {th }}$ St., Fargo, ND 58105.

**Biosciences Research Laboratory, USDA-ARS, Fargo, 1605 Albrecht Blvd., Fargo, ND 58105.

The glassy-winged sharpshooter (GWSS), Homalodisca coagulata, is a significant economic threat to many crops because it serves as vector for the bacterial pathogen, Xylella fastidiosa. This bacterium is a xylem-limited pathogen and is transmitted to the plants while the insects are feeding on the xylem sap. Glassy-winged sharpshooters have piercing, sucking mouthparts withmaxillary stylets of sufficient rigidity to allow penetration of woody stems including mature grape vines. We have examined the ultrastructure of the mouthparts of the GWSS using SEM techniques. The terminal components of the mouthparts consist of a labrum, a labium and a stylet bundle or fascicule (Fig. 1). The stylet fascicule is encased in the segmented labium and is composed of two mandibular and two maxillary stylets (Fig. 2). The mandibular stylets, with serrated outer margins, are located laterally to the maxillary stylets (Fig. 3). The maxillary stylets can be extended and withdrawn independently from the mandibular stylets. The two maxillary stylets are cresentshaped along their length forming a smooth hollow tubular structure which have a sight dentation near their tip (Fig. 4). The two joints, which attach the maxillary stylet to its mate are similar to that of a mortise and tenon type of joint (Fig. 5) and appear to run the length of the tube. When the stylet bundle is viewed in cross section (Fig. 5), the salivary duct within the maxillary stylet and the food canal formed by these interlocking stylets is evident. The GWSS is a salivary sheath type feeder, which means that during plant penetration it secretes lipoproteinaceous saliva that forms an encasement around the stylet fascicule (Fig. 6). These sheaths may be singular or branched depending upon the probing behavior of the insect and penetrate epidermal, cortical parenchyma, and lignified tissues before reaching the vessel elements of the plant host.

Fig. 1. Terminal portion of the GWSS mouthparts showing the labrum $(l r)$, labium $(l b)$, labial groove (arrow), and stylet fascicule (arrowhead).

Fig. 2. The serrated mandibular stylets $(m d)$ shown encasing the unextended maxillary stylets $(m x)$.

Fig. 3. The stylet fascicule extended beyond the labium $(l b)$, showing the serrated mandibular stylets $(m d)$, and the smooth maxillary stylets $(m x)$.

Fig. 4. The terminal end of the joined maxillary stylets $(m x)$ showing the dentations near their tip (arrows).

Fig. 5. A cross-section of the stylet fascicule showing the maxillary $(m x)$ and mandibular ( $m d)$ stylets, food canal $(f c)$, salivary ducts (arrowhead), and interlocking stylet joints (arrows).

Fig. 6. A cross-section of a sunflower stem showing a branched salivary sheath (arrow) penetrating to the xylem tissue (arrowhead). 


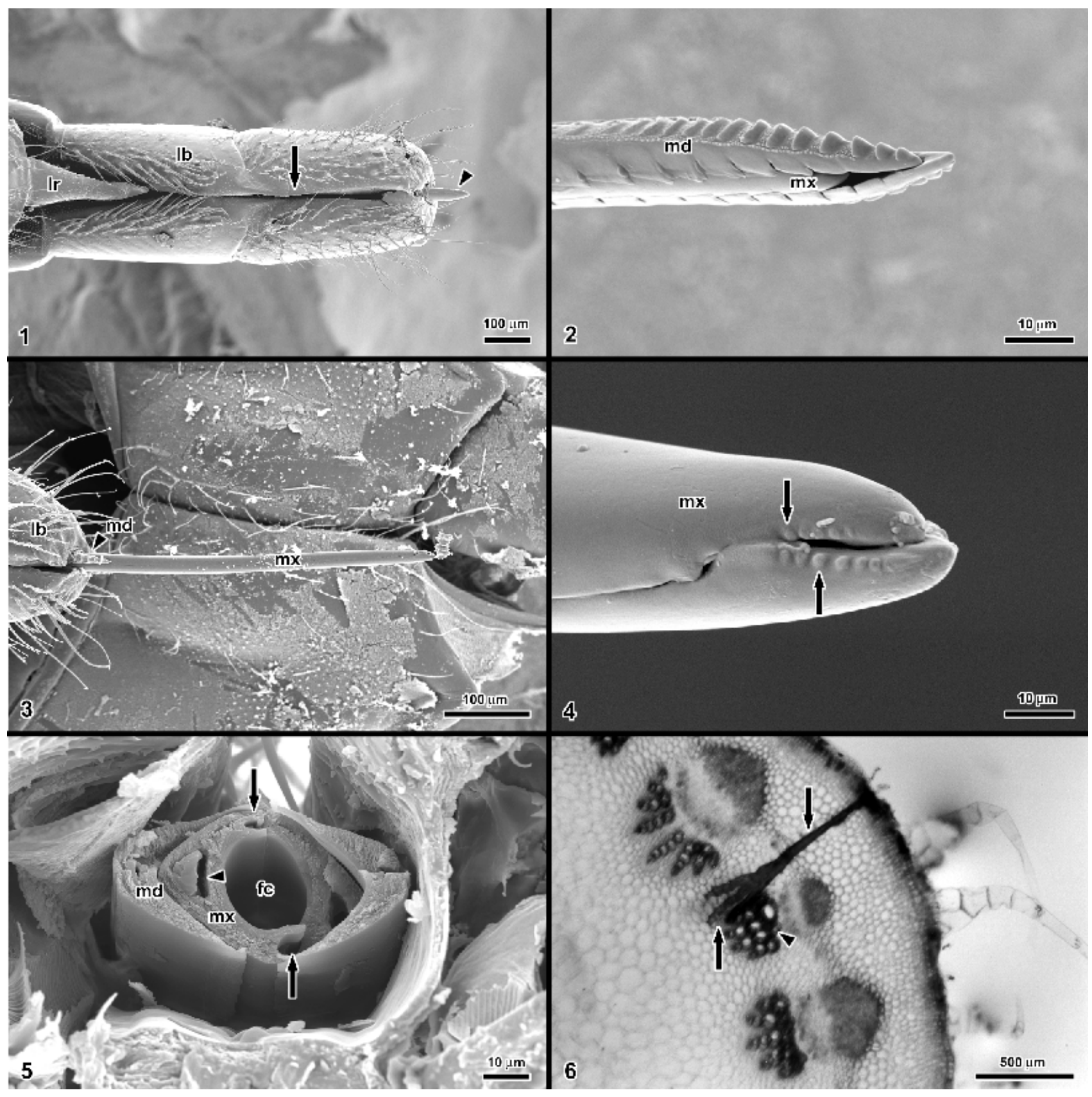

